\title{
Problems and Political Suggestions of Export Trade of Bamboo Products in Northern Fujian
}

\author{
Wang Bo \\ Fuzhou University of International Studies and Trade
}

\begin{abstract}
Northern Fujian has rich bamboo resources of wide varieties and is known as "the hometown of bamboo shoots and bamboo in China", and Northern Fujian currently has three hometowns of bamboo in China and two hometowns of bamboo with Chinese characteristics. This paper analyzes the export trade development of bamboo products in Northern Fujian under the new normal of economy, then discusses the main characteristics, the current status about the export of enterprises, the existing problems, reasons and other aspects, and finally puts forward countermeasures and suggestions for the bamboo industry in Northern Fujian to respond to the new normal construction of economy in China, thereby promoting the export trade development of bamboo products in Northern Fujian.
\end{abstract}

\section{Keywords-Bamboo products; Export trade}

\section{INTRODUCTION}

Northern Fujian Region is one of the important forest areas in the south of our country, and is known as "The hometown of bamboo", and as an important component of forest resources in Northern Fujian Region, bamboo forest has also provided a good resource support for the economic development and bamboo industry development in Northern Fujian Region. From 1980s, enterprises engaged in the production and process of bamboo shoots, and bamboo as raw materials as well as the export sales thereof were constantly increased in Northern Fujian Region, but due to the selfdevelopment restriction of enterprises and the increasingly severe global economic environment, the export trade of bamboo products in Northern Fujian was also faced many problems. At present, Chinese economy has walked towards a kind of new normal, which is no doubt a new opportunity and challenge for the bamboo industry in Northern Fujian. This article analyzes the current export status of bamboo product enterprises in Northern Fujian, the existing problems and reasons, and put forward relevant development suggestions, which can be good for further solving the problems faced by bamboo product enterprises in Northern Fujian Region, make the bamboo manufacture in Northern Fujian Region obtain breakthrough, so as to promote the degree of export trade for bamboo industry manufactures in Northern Fujian Region.

\section{CURRENT STATUS OF THE EXPORT TRADE OF BAMBOO INDUSTRY IN NORTHERN FUJIAN}

Since the World Economic Crises in 2008, although Northern Fujian Region constantly adjusted the processing industry of bamboo products, in the face of the macroscopic influence of depressed world economy and downward increase speed of domestic economy, the bamboo product processing industry in Northern Fujian Region has bidden farewell to the high-speed development period, and the export trade of bamboo products in Northern Fujian is also faced with a brand new mode, and the export scale of bamboo products is also constantly enlarged, and the varies of bamboo products are increasingly enriched; meanwhile, due to the increasingly high requirements for the export quality of bamboo products, this has become a new normal for the foreign trade commercial development of bamboo products in Northern Fujian.

\section{A. The Export Growth Slows Down}

As per the statistical yearbook of Fujian and the relevant data of China, the production value of bamboo products processing industry in Northern Fujian Region of the entire city (Nanping City) in 2015 was USD 623 million, of which the scale enterprise completion value was USD 223 million, which was increased by $42 \%$ than that in 2014, and the bamboo product processing has become one of the seven big leading industries in Nanping City, of which there were above $65 \%$ of bamboo products being exported to overseas countries. According to the relevant data of Nanping City Statistic Bureau, in 2015, the totally exported bamboo and straw products in Nanping City in 2015 were 75,999 batches, and the accumulated gross export was USD 187 million, and the ratio of the foreign trade of bamboo products in Northern Fujian in the total value of foreign trade for national bamboo products was $1.14 \%$, ranking the 5 th nationwide. In the recent years, the foreign trade growth speed of bamboo products in Nanping City has been quite slow, and the annual average increase rate was $3.7 \%$, which was far lower than $12.34 \%$ of the increase speed for the total value of foreign trade for bamboo products in our country during the same period.

Author: Wang Bo (1970- ), male, Associate Professor, Fuzhou University of International Studies and Trade. E-mail: 83695363@qq.com 
TABLE I. EXPORT CONDITIONS ABOUt THE BAMBOO AND WOOD Products IN FUJIAN PROVINCE FROM 2011 TO 2015

\begin{tabular}{cccccc}
\hline Year & 2011 & 2012 & 2013 & 2014 & 2015 \\
$\begin{array}{c}\text { Export batch (ten thousand } \\
\text { batches) }\end{array}$ & 6.35 & 6.03 & 6.36 & 7 & 7.6 \\
$\begin{array}{c}\text { Export amount (billions of } \\
\text { dollars) }\end{array}$ & 1.26 & 1.3 & 1.49 & 1.65 & 1.88 \\
\hline
\end{tabular}

\section{B. Comprehensive Increase in Export Trade Volume}

In the recent years, along with the constantly in-depth development of bamboo product resources in Northern Fujian Region, the export types of bamboo products has also become increasingly rich. Currently, the exported bamboo products in Northern Fujian mainly include seven types, i.e., the traditional bamboo products, bamboo wood artificial board, bamboo shoots processing products, bamboo pulp papers, bamboo fiber products, bamboo charcoal and bamboo leaf extract, with above 2,000 varieties. At present, merely good bamboo products are exported, and mainly include bamboo wood types of household products, bamboo shoots processed goods, and bamboo fiber products, especially the ratio of bamboo fiber products in the export of bamboo products, which has also been gradually improved, and the export structure of bamboo products has also been further optimized. Meanwhile, the export value of main bamboo products in Northern Fujian Region is also constantly and comprehensively increased, and the average increase rate can reach up to about $30 \%$, of which the export of indoor decoration materials, kitchen utensils, bamboo artware, bamboo shoots, bamboo charcoal and other series of relevant products can rank top in Fujian Province and the entire country.

\section{Increase of Export Market}

Over the past decade, the export enterprises of bamboo products in Northern Fujian has been engaged in comprehensively exploiting the international market, and under the endeavors made by these export enterprises, the diversified pattern for the international export market of bamboo products in Northern Fujian Region is now forming.
${ }^{\text {a. }}$ Data Source: CIQ data statistics of Quarantine Bureau Up till February, 2016, the bamboo products in Northern Fujian Region have been exported to 107 countries and regions, but as can be seen from the current trade conditions, America, Japan, European Union and other countries still rank Top 3 ahead of the export of bamboo products in Northern Fujian Region. As can be seen from the relevant data about the foreign trade of bamboo products in Northern Fujian in 2015, America occupied $21.45 \%$, the goods value was USD 54 million, the export volume of European Union occupied $14.45 \%$, and the goods value was about USD 36 million, but the entire Asian region is the most main area for the export of bamboo products in Northern Fujian, and occupies above a half of the export of bamboo products in Northern Fujian, of which the total export volume of Japan was USD 47.76 million, the total export volume of Korea was USD 34.89 million, the total export volume of ASEAN was USD 21.23 million, and that for other regions was about USD 21.99 million.

Besides, as one of the main characteristics for the current status about the export of bamboo products in Northern Fujian, the requirement of enterprises for bamboo products has been increasingly high, and this can exert an important role in constantly reinforcing the strength of bamboo product export enterprises in Northern Fujian, and facilitate the promotion of enterprise production technology improvement, etc. For instance, in February, 2016, Fujian Dushi Wood Industry Co., Ltd. became the first quality safety model enterprise engaged in the export of bamboo and straw products in Fujian Province, which was meaningful to drive the improvement of quality safety level for the export of bamboo and straw products in Fujian Province, and promote the export of bamboo and straw products.

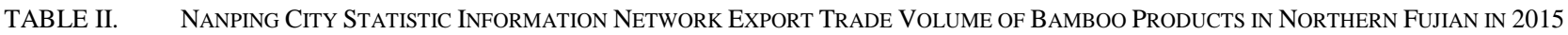

\begin{tabular}{ccccccc}
\hline Country (Region) & America & Japan & $\begin{array}{c}\text { European } \\
\text { Union }\end{array}$ & Korea & ASEAN & Others \\
\hline $\begin{array}{c}\text { Export trade volume (million } \\
\text { dollars) }\end{array}$ & 5400 & 4776 & 3600 & 3489 & 2123 & 2199 \\
\hline
\end{tabular}

\section{MAIN PROBLEMS FOR THE EXPORT TRADE OF BAMBOO PRODUCT ENTERPRISES IN NORTHERN FUJIAN}

\section{A. Increase in Production Cost}

Currently, the bamboo product enterprises in Northern Fujian are facing problems such as the increase of personnel salary, the increase in the price of auxiliary materials, the gradual increase of logistics, water and electricity expenses, and according to the statistic data investigation of Nanping City, the average salary for the exported bamboo product processing enterprises in Nanping City in 2015 was $11.15 \%$, the increase rate of logistic expenses was $9.03 \%$, the increase rate of water and electricity expenses was increased by $4.67 \%$, and the enterprise production expense burden was further increased. Due to the economic recovery and weakness abroad, the internal exchange rate has big fluctuation, so it is hard to increase the export price of bamboo products. Under the dual 
effect at home and abroad, enterprises are facing the problem of constant increase in the manufacturing cost of bamboo products, but relatively few profits, and this will not only seriously strike the enthusiasm of enterprise operation, but also form a kind of vicious circle, cause the low development of bamboo processing enterprises in Northern Fujian and the backward operation management, and then make it hard to ensure the quality stability of bamboo products.

\section{B. Low Production Efficiency}

As per the relevant data about the statistical yearbook of Nanping City, there are currently above 280 export enterprises of bamboo products in Nanping City in total, but there are merely less than 10 enterprises for which the export volume can exceed USD 10 million, and above 90 enterprises for which the export volume is less than USD 1 million, and except the bamboo product trade company, there are merely above 130 enterprises possessing actual bamboo product production and processing, and the average export volume for these enterprises is about USD 450,000, and enterprises with small quantity, small scale, weak radiation driving effect, and few bamboo products can exert a leading effect in the bamboo product trade of Northern Fujian

But most small and medium-sized enterprises engaged in the export of bamboo products have problems such as simple manufacturing equipment, low production efficiency, big manufacturing material consumption quantity, backward manufacturing technology, low product additional value, serious resource waste, and backward industrial level, and this will not only cause the slow scaled-development of enterprises and the insufficient aftereffect, but also seriously influence the competitiveness of Northern Fujian Region in the export trade of bamboo products, and in the competition with foreign bamboo products, the bamboo products in Northern Fujian Region is more easily in an inferior position. Meanwhile, due to production efficiency problems, many enterprises will hesitate in the face of many export trade opportunities, and worry about that their capacity and production strength cannot meet the relevant requirements of the opposite party, and then loose the opportunity for further development.

TABLE III. OVERVIEW OF THE EXPORT ENTERPRISES OF BAMBOO PRODUCTS IN NORTHERN FUJIAN IN 2015

\begin{tabular}{cccc}
\hline Name & $\begin{array}{c}\text { Total } \\
\text { Quantity of } \\
\text { Enterprises }\end{array}$ & $\begin{array}{c}\text { The export volume is more than } \\
\text { USD 10 million }\end{array}$ & $\begin{array}{c}\text { The export amount is less } \\
\text { than USD 1 million }\end{array}$ \\
\hline $\begin{array}{c}\text { Amount } \\
\text { (quantity) }\end{array}$ & 283 & 7 & 96 \\
\hline
\end{tabular}

c. Data Source: Nanping City Statistic Information Network

\section{Backward Management Level}

At present, as for the export of bamboo product export trade in Northern Fujian, enterprises commonly have insufficient management awareness, and the problems of backward management level. Since the enterprises in Northern Fujian Region are mostly small and medium-sized enterprises, most enterprises generally rely on family type management, and the management post in enterprises is also generally taken by relevant family members, so it is hard for professional management personnel to enter into these enterprise, which will result in the difficulty to implement the enterprise management mode to some extent, and the difficulty to obtain material development. There are also many enterprises which are eager for quick success and instant benefits, pay less attention to enterprise management, lack in reinforcing the long-term plan of enterprise management, with fuzzy the enterprise development direction, objective and key plan, etc., and many export projects just blindly follow, without even feasible argument, which has caused the loss of macroeconomic control for the export trade of bamboo products in Northern Fujian Region, and the difficulty to form regional group advantages. Besides, many small enterprises have "easily satisfied" thought, and due to the lack in leading enterprises driving the industrial development, the regional overall development speed is low.

Of course, there are also some excellent enterprises in our city for which the management inspection can be regarded as the reference, such as "Dushi", "Senzhu", "Yuanqiao", "Fuxian" and other leading enterprises' brands, which have obtained the famous brand of Fujian Province. Thus, medium small and micro-sized enterprises can fully explore through referring to the experience of excellent enterprises, create more suitable management mode and play its own advantages, make the enterprise become stronger, and promote the bamboo industry development in Northern Fujian.

\section{Extensively Concentrated Export Market}

For now, the foreign trade of bamboo products in Northern Fujian is excessively focused on American, Japanese, European Union and Korean markets, and the share of foreign trade for the bamboo products of Northern Fujian in these four countries or regions is about $70 \%$. Since the foreign trade market is excessively concentrated, this has made the capacity for bamboo product companies to resist risk, so it will generate a bad influence on the constant growth for the foreign trade of bamboo products, and as you can imagine, once these countries cut down the demand for bamboo products in Northern Fujian Region, this may influence the foreign trade development of bamboo product exporters in Northern Fujian Region and even China. The shares of ASEAN, Canada, Australia and even Taiwan of China are obviously less than the aforementioned four countries, and the export prospect for these countries is actually broad, and remains to be continuously subject to market excavation, and then promote the export trade growth of bamboo products in Northern Fujian, and this won't easily make the enterprises of Northern Fujian Region get into the excessively concentrated conditions of export market. 


\begin{tabular}{ccccc}
\hline $\begin{array}{c}\text { Country/R } \\
\text { egion }\end{array}$ & $\begin{array}{c}\text { Americ } \\
\mathrm{a}\end{array}$ & $\begin{array}{c}\text { Japa } \\
\mathrm{n}\end{array}$ & $\begin{array}{c}\text { Europe } \\
\text { an } \\
\text { Union }\end{array}$ & $\begin{array}{c}\text { Kore } \\
\mathrm{a}\end{array}$ \\
\hline Share & $21.45 \%$ & $19 \%$ & $14.45 \%$ & $14 \%$ \\
\hline \multicolumn{1}{c}{} \\
erated Trade Competition of Domestic and Overseas
\end{tabular}

The bamboo product processing enterprises in Northern Fujian Region are also facing the challenge of further aggravated trade competition in trade export. Along with the fast development of bamboo product processing industry at home, the position in export trade is constantly improved, including Zhejiang, Jiangsu and other provinces, which have gradually increased the degree of emphasis on the bamboo product processing and trade export, and lots of bamboo product processing enterprises have also sprung up in Zhejiang, Jiangsu and other places, and these enterprises constantly conduct technical upgrading based on the developed economic conditions in local, and the bamboo product processing industry obtains fast development, which has caused certain challenge to the bamboo product processing enterprises of Northern Fujian. Besides, in order to ensure production, the raw materials (including bamboo and bamboo shoots) for most bamboo product processing enterprise in Zhejiang, Jiangsu and other places are purchased from Northern Fujian Region at a high price, and from 2012, there are about 100,000 tons of bamboo shoots in Northern Fujian Region being annually flown into other provinces, and can occupy $40 \%$ of the total quantity of bamboo shoots in Northern Fujian Region, but the loss of many raw materials has not only damaged the advantageous position of bamboo resource in Northern Fujian Region, but also generated influence to the bamboo product production in Northern Fujian Region.

Being influenced by the constant upgrading of technical barriers in the international market, the access requirements of many export countries and regions have become increasingly strict for bamboo products, and the relevant inspection technology measures have emerged one by one, which has largely enlarged the resistance for the export of bamboo products in Northern Fujian. For instance, in July, 2012, America released and made valid the Formaldehyde Standard Bill for Compound Wooden Products, the relevant formaldehyde inspection of bamboo products was stricter. In March, 2013, European Union officially published the Labeling Act for the Country of Origin, and the objective was to ensure that the buyers clearly knew about the country of origin for the imported commodities selling in Europe. This Act has made clear that FSC "identity card" must be obtained for wooden

\begin{tabular}{ccccc}
$\begin{array}{c}\text { ASEA } \\
\mathrm{N}\end{array}$ & Canada & Australia & $\begin{array}{c}\text { Taiwan, } \\
\text { China }\end{array}$ & $\begin{array}{c}\text { Othe } \\
\text { rs }\end{array}$ \\
\hline $8 \%$ & $8 \%$ & $6 \%$ & $5 \%$ & $4.1 \%$ \\
\hline
\end{tabular}
products exported to European Union market, i.e., verifying that the wood purchased by the manufacturer is from legally developed forest area. Besides, many European America large-scaled purchasers also put forward authentication requirements for export enterprises, and the authentication contents involve personnel welfare, social responsibilities, environment protection, etc.; the increasingly strict "technical barriers" have caused pressure on the development of medium and small-sized bamboo product processing enterprises, and influenced the export of bamboo products in Northern Fujian Region.

\section{IMPROVEMENT OF THE POLITICAL SUGGESTIONS FOR THE EXPORT TRADE OF BAMBOO PRODUCTS IN NORTHERN FUJIAN}

\section{A. Accelerate Industrial Integration}

The urgent task for the development of bamboo product enterprises is to further reinforce the transformation and upgrading of bamboo product processing industry in Northern Fujian Region, gradually eliminate backward productivity, and gradually develop towards brand strategy from originally simple resource collection, and it is requested to follow the requirements of focusing on the big ones, and then constantly expand operation strategy recombination in capital, operation scale and enterprise function. It is requested to constantly encourage middle and small-sized enterprises to conduct optimization and reorganization, prohibit some extensive production enterprises, eliminate backward productivity, gradually improve mechanical manufacturing degree, and make the consumption material cost and labor cost in enterprises decrease validly, reinforce enterprise benefits, decrease resource waste, and become some the group enterprises integrating industry and trade as well as multiple functions, and gradually improve the influence of bamboo product processing enterprises of Northern Fujian Region in the international market.

\section{B. Reinforce the Export Support for Bamboo Product Enterprises}

In order to constantly promote the trade development of bamboo product enterprise, it is also requested to constantly change the government management awareness, reinforce the government service function, further reinforce the service support of relevant government department for 
bamboo product enterprises, and formulate more preferential policies for the export of bamboo product enterprises, improve the enterprise operation efficiency, decrease the administrative cost of enterprises, and better escort the constant growth of enterprises. Secondly, it is also requested to play the advantages of government department in financial service, promote bamboo product enterprises establish cooperation mechanism with the bank, trust institution, etc., further simplify the loan procedures of bamboo product processing enterprises, enlarge the credit line for middle and small-sized enterprises engaged in bamboo product processing, and better validly help enterprises solve fund turnover problems, and through further discussing various service modes, establish bamboo product foreign trade credit insurance platform, formulate and implement tax refunding and supplementary difference in the foreign trade of bamboo products, the award for foreign trade exceeding the cardinal number, and the foreign trade credit premium subsidiary, etc.

\section{Formulate Relevant Talent Policy}

It is requested to constantly reinforce the talent team construction of bamboo product enterprises in Northern Fujian, especially pay attention to the cultivation and inheritance of technical talents, build a good learning and development environment, fully play the "teaching, helping and leading" effect of old technical talents, and encourage new ones to work hard, boldly innovate, and meanwhile, actively help bamboo product enterprise employees solve work and production problems, improve the employees' sense of belonging for the enterprise, and keep the stability of personnel team. Besides, it is also requested to actively focus on product development innovation, and through relying on new technology, and new materials, conduct the R\&D of new technology and new products, improve the cultural taste of products, and integrate the ethnic culture reflected in the product with the modernized culture and national culture, and realize inheritance and innovation. It is requested to energetically give full play to products with proprietary intellectual property rights, and realize its own advantages with the high-tech contents and high additional value of products in the international market, and improve the influence in the international market.

\section{Reinforce Brand Construction}

It is requested to constantly reinforce the brand contraction of bamboo product processing trade, form a batch of bamboo product processing leading enterprises with Northern Fujian characteristics, and improve the brand influence of bamboo products in Northern Fujian. It is also requested to constantly regard the creation of core brand as the strategic objective, and then improve the additional value of product through product innovation, the change of traditional fabrication technology and other modes, and then through further cooperating with the relevant researches, colleges and other institutions, attract more senior management talents, technical talents, and improve the enterprise management level, and lay a good foundation for brand construction and development. Besides, it is also requested to actively use all opportunities, to increase the opportunities to display bamboo products of Northern Fujian on international stages, fully utilize international famous expos and some large-scaled international activity opportunities, conduct brand marketing, and promote brand influence; pay attention to the construction development of e-commerce platform, constantly encourage enterprises to improve product influence through cross-border ecommerce platform and other modes, and make overseas consumers have more opportunities to contact with the bamboo products of Northern Fujian; the government should constantly support enterprises to confidentially "go out', and encourage enterprises to establish sales network at abroad, open sales window and establish trade relation with foreign importers, wholesalers, chain stores, etc.

\section{CONCLUSION}

This article firstly discusses the current status and existing problems about the export trade development of bamboo industry in Northern Fujian, and it mainly includes: the increase in production cost, low production efficiency, backward management level, extensively concentrated export market, intensifying competition for domestic and overseas bamboo product trade; and then on this basis, it has put forward the political suggestions for reinforcing the export trade of bamboo products in Northern Fujian, which include accelerating industrial integration, reinforcing the export support for bamboo product enterprises, formulating relevant talent policies, and reinforcing brand construction.

\section{REFERENCES}

[1] Huang Hangyan. Countermeasures for the Development of Wood and Bamboo Processing Industry in Northern Fujian [J]. Forestry of China, 2008 (03): 11-13.

[2] Song Jing. Analysis about the Industrial Development for the Export of Bamboo Products in Fujian [J]. Agricultural Development \& Equipments, 2016 (01): 22-25.

[3] Wang Xianying. Analysis on the Utilization of Bamboo Industry Resources in Northern Fujian and the Research about the Development Trend [D]. Fuzhou: Fujian Agriculture and Forestry University, 2015, 16-18.

[4] Wu Dongling. Form Innovation Analysis and Application of Bamboo Product Form [J]. Mechanical Design, 2013 (07): 115-117.

[5] Zheng Zhaofei. Current status and development countermeasure sfor bamboo industry in Northern Fujian [J]. World Bamboo and Rattan, 2009 (04): 33-36.

[6] Deng Bangkun. Discussion about the Innovative Development Trend of Bamboo Product Enterprises [J]. Scientific and Technical Innovation and Application, 2016 (26): 264.

[7] Ge Xiaohua. The Road of Spanning Development for Bamboo Industry in Northern Fujian_-Investigation and Thought about the Cultivation and Development of Hundred Billions of Bamboo Industry In Nanping City [J]. Fujian Forestry, 2014 (04): 4-6. 